\title{
Bismuth Vanadium Oxide Can Promote Growth and Activity in Arabidopsis thaliana
}

\author{
Cong Gao, Shuai Lu, Yongzhou Wang, Hao Xu, Xiaoxiao Gao, Yiwen Gu, Hongyun Xuan, \\ Baohua Wang *, Huihua Yuan* and Yunying Cao *
}

School of Life Sciences, Nantong University, Nantong, China

The excellent properties of nanomaterials have been confirmed in many fields, but their effects on plants are still unclear. In this study, different concentrations of bismuth vanadate (BV) were added to the growth medium to analyze the growth of seedlings, including taproots, lateral roots, leaf stomata, root activity, and superoxide anion $\mathrm{O}_{2}{ }^{--}$generation.

OPEN ACCESS

Edited by:

Qihui Zhou,

Qingdao University, China

Reviewed by:

Xiaojun Zhou,

Donghua University, China

Gang Zhao,

University of Jinan, China

Shige Wang,

University of Shanghai for Science and

Technology, China

*Correspondence: Yunying Cao

cyy@ntu.edu.cn

Huihua Yuan

yuanhh@ntu.edu.cn

Baohua Wang

bhwang@ntu.edu.cn

Specialty section:

This article was submitted to

Nanoscience,

a section of the journal

Frontiers in Chemistry

Received: 28 August 2021 Accepted: 30 September 2021 Published: 11 November 2021

Citation:

Gao C, Lu S, Wang Y, Xu H, Gao X, Gu $Y$, Xuan H, Wang B, Yuan $H$ and Cao Y (2021) Bismuth Vanadium Oxide Can Promote Growth and Activity in Arabidopsis thaliana.

Front. Chem. 9:766078.

doi: 10.3389/fchem.2021.766078 Gene expression levels related to root growth were determined by quantitative PCR in Arabidopsis thaliana. The results showed that BV promoted the growth of taproots and the development of lateral roots, enhanced the length of the extension zone in roots, increased the number and size of leaf stomata and root activity, reduced the accumulation of ROS in seedlings, and changed the expression levels of genes related to polyamines or hormones. At the same time, we investigated the antibacterial activity of BV against a variety of common pathogens causing crop diseases. The results showed that BV could effectively inhibit the growth of Fusarium wilt of cotton and rice sheath blight. These results provide a new prospect for the development of nanomaterial-assisted plants, which is expected to become one of the ways to solve the problem of controlling and promoting the development of plants. At the same time, it also provides a reference for the study of the effect of BV on plants.

Keywords: bismuth vanadium, Arabidopsis thaliana, roots, reactive oxygen generation, gene expression, bacteriostasis

\section{INTRODUCTION}

Compared with traditional materials, nanomaterials have many advantages and are applied in the information industry, environmental industry, energy (Zhao et al., 2018; Hao et al., 2021; Zhao et al., 2021) and environmental protection, biological medicine, and other fields (Castiglione et al., 2011). The growth and development of plants are regulated by many factors, such as temperature and hormones (Brandhoff et al., 2017; Ibañez et al., 2017; Kim et al., 2017; Sun et al., 2019; GómezMerino et al., 2020). An increasing number of studies have shown that nanomaterials also have an impact on the growth and development of plants (Thuesombat et al., 2014). For example, modified polystyrene nanomaterials with different polarities could inhibit root development in Arabidopsis (Sun et al., 2020). Copper oxide nanoparticles (CuONPs) regulated the phenotype of mung bean (Nair et al., 2014). CuONPs can gradually decrease the mitotic index of onion root tips gradually and increase the abnormal index (Nagaonkar et al., 2015). Furthermore, the effects of nano- $\mathrm{TiO}_{2}$ foliage intervention on cadmium bioaccumulation, stress kinase, and potential dietary health risks in cowpea plants were also reported (Ogunkunle et al., 2020). Moreover, the degree of lignification of the xylem in roots and stems of fenugreek treated with nanosilicon materials was significantly higher 
than that of control plants (Nazaralian et al., 2017). Most of the nanomaterials mentioned above showed toxic effects on plants; however, some of them demonstrated a positive role. A study reported that graphene oxide promoted the growth of watermelon, including increasing root length, leaf area, leaf number, and flower bud formation (Park et al., 2020). Multiwalled carbon nanotubes (MWCNTs) could stimulate the seed germination of three important crops (barley, soybean, and maize) and enhance the root length in Phaseolus mungo seedlings and the germination index of Brassica juncea at low concentrations (Ghodake et al., 2010; Mondal et al., 2011; Lahiani et al., 2013). However, their application in plantrelated fields is still limited, and due to the variety and different characteristics of nanomaterials, different materials show different effects on plants.

Metal vanadates have been widely used in applications such as batteries, implantable cardiac defibrillators, and photocatalysts (Sivakumar et al., 2015). Specifically, bismuth vanadate nanomaterials (herein referred to as BVs) have emerged as promising candidates due to their unique nontoxicity, chemical stability, optical properties, and ferro-elastic properties (Sarkar et al., 2012). Various applications of BV have been well-studied in eco-friendly yellow pigments, water splitting processes, sensors, and pollutant degradation. Recently, BV has garnered notable attention in biological applications. A BV composite material exhibited excellent potential for the inactivation of Escherichia coli (Sharma et al., 2016; Guan et al., 2018; Regmi et al., 2018). This study provided evidence about the positive effects of BV nanomaterials on the microbiome. However, currently, no or few attempts have been made to explore the effect of BV nanomaterials on plants. Therefore, the objective of this study was to use Arabidopsis thaliana as a model plant to determine the effect of BV on some factors, including the length of taproots, the number of lateral roots, the number and size of stomata in leaves, the activity of plant roots, superoxide anion $\mathrm{O}_{2}{ }^{--}$generation and the accumulation of BV in seedlings, antimicrobial activity, and the expression of genes related to roots. This evaluation was based on determining the effects of applying different concentrations of BV on seedlings to clarify the effect of BV on Arabidopsis thaliana.

\section{MATERIALS AND METHODS}

\section{Plant Material}

Seeds of Arabidopsis thaliana Columbia-0 (Col-0) were surfacesterilized with $70 \%$ ethanol and $20 \%$ bleach. Materials were grown at $22^{\circ} \mathrm{C} / 20^{\circ} \mathrm{C}$ under a photoperiod with $16 \mathrm{~h}$ of light and $8 \mathrm{~h}$ of dark and a light intensity of $100 \mu \mathrm{mol} \mathrm{m}^{-2} \mathrm{~s}^{-1}$ in an incubator (QY-14; Nanjing Quanyou Electronic Technology Co., Ltd, China).

\section{Preparation and Characterization of BV}

$\mathrm{Bi}\left(\mathrm{NO}_{3}\right)_{3} \cdot 5 \mathrm{H}_{2} \mathrm{O}(2.1830 \mathrm{~g})$ and EDTA $(4 \mathrm{~g})$ were dissolved in dilute $\mathrm{HNO}_{3}$ solution $\left(50 \mathrm{ml}, 2 \mathrm{mmol} \mathrm{L}{ }^{-1}\right)$ and stirred at $90^{\circ} \mathrm{C}$ for $30 \mathrm{~min}\left(200 \mathrm{r} \mathrm{min}^{-1}\right)$ to obtain solution $\mathrm{A} . \mathrm{NH}_{4} \mathrm{VO}_{3}(0.5260 \mathrm{~g})$ was dissolved in deionized water $(50 \mathrm{ml})$ at $60^{\circ} \mathrm{C}$ to obtain solution $\mathrm{B}$. Then, solution $\mathrm{B}$ was mixed with solution $\mathrm{A}$, and the $\mathrm{pH}$ was adjusted to 7 by adding $\mathrm{NH}_{4} \mathrm{OH}$. The abovementioned mixed solution was stirred for $1 \mathrm{~h}$ at $50^{\circ} \mathrm{C}$, poured into a $150-\mathrm{ml}$ Teflon-lined stainless-steel autoclave, and maintained at $180^{\circ} \mathrm{C}$ for $6 \mathrm{~h}$. The prepared precipitate was washed with ethanol and deionized water several times and vacuum-dried at $75^{\circ} \mathrm{C}$ overnight to form $\mathrm{BV}$ nanomaterials. Sample morphology and surface elemental composition were examined by scanning electron microscopy (SEM; JSM6510, JEOL, Japan) coupled with energy-dispersive spectrometry (EDS) at an accelerating voltage of $10 \mathrm{kV}$. X-ray diffraction (XRD; Ultima IV, Rigaku, Japan) patterns of the samples were recorded by using high-intensity $\mathrm{Cu} K$ a radiation $(\lambda=0.154 \mathrm{~nm})$ in the range of $2 \theta=10^{\circ}-80^{\circ}$ at a scan rate of $5^{\circ} \mathrm{min}^{-1}$.

\section{Preparation of Roots for Analysis}

With respect to plants grown in solid media, Arabidopsis thaliana seeds were germinated on a square plate $(10 \mathrm{~cm} \times$ $10 \mathrm{~cm}$ ) that contained sterilized solidified half-strength MS (Sigma-Aldrich, St. Louis, MO, United States) media consisting of $0.8 \%$ agar (Affymetrix, Inc. Cleveland, Ohio, United States) and $1 \%$ sucrose. Ten grams of BV powder was dissolved in $1 \mathrm{~L}$ of deionized water and sterilized in an autoclave (SANYO Labo Autoclave, MLS-3020). The BV solution that had been sonicated for $1 \mathrm{~h}$ and was blended with a sterilized halfstrength MS medium by stirring with $0,20,50,100$, and $200 \mu \mathrm{g} \mathrm{ml}^{-1}$ nanomaterials and the resulting medium (hereafter referred to as the BV/MS medium). In total, 30-40 seeds were planted in the $\mathrm{BV} / \mathrm{MS}$ medium, placed at $4^{\circ} \mathrm{C}$ for 2 days, and then transferred to a growth chamber as described above. The roots were imaged using a scanner, and the primary root length was measured using ImageJ software (National Institutes of Health, United States) after 6 days of exposure. The lateral root number was analyzed after 11 days of exposure. The roots of the plants exposed to nanomaterials for 6 days were stained with propidium iodide for viability testing of the meristem, extension zone length, tip diameter, and rootcap size of the primary root as described previously (NapsucialyMendivil et al., 2014).

\section{Measurement of BV Content}

Six-day-old control and BV-treated Arabidopsis thaliana were divided into roots and leaves, dried $\left(105^{\circ} \mathrm{C}\right.$ for half an hour and $80^{\circ} \mathrm{C}$ for 3 days), and ground into powder. Subsequently, the powder was used to measure the BV content using XRD.

\section{Measurement of the Number and Size of Stomata}

Six-day-old control and BV-treated Arabidopsis thaliana were dehydrated with different concentrations of ethanol $(30,50,70$, 80 , and $90 \%$ for $20 \mathrm{~min}$ and $100 \%$ for $40 \mathrm{~min}$, repeated three times), dried by using a critical point dryer (EM CPD 300, Leica, Germany), and coated with a film with ion sputtering equipment (EM ACE 600, Leica, Germany). The SEM (JSM6510, JEOL, Japan) was used to take photos of dehydrated materials, and the photos were imported into ImageJ to count the number and size of stomata. The calculation formula of stomatal density (SD) was 
as follows: $\mathrm{SD}=\mathrm{N} / \mathrm{S}$, where $\mathrm{N}$ is the number of stomata in the visual field and $S$ is the area of the visual field. The formula for calculating the stomatal size (SS) was SS $=\mathrm{L}$ (length) ${ }^{\star} \mathrm{W}$ (width) $\star 3.14 / 4$.

\section{Detection of Superoxide Anion Radical $\mathrm{O}_{2}{ }^{--}$ and Root Activity}

To visualize $\mathrm{O}_{2}{ }^{--}$and root activity in plants in situ, nitroblue tetrazolium (NBT) and 2, 3, 5-triphenyl tetrazolium chloride (TTC) staining was performed, respectively, as described previously (Kong et al., 2018; Tanaka et al., 2020) and modified slightly. $\mathrm{O}_{2}{ }^{--}$generated in seedlings was measured by incubating the plants in $1 \% \mathrm{NBT}$ within $20 \mathrm{mmol} \mathrm{L}^{-1}$ potassium phosphate, washing with distilled water, and decolorizing with $70 \%$ ethanol solution in water at $90^{\circ} \mathrm{C}$ for $20 \mathrm{~min}$. The root activity was measured by incubating the plants in $2 \%$ TTC at $37^{\circ} \mathrm{C}$ for $5 \mathrm{~h}$. Images of the plants or roots were obtained under brightfield illumination.

\section{Antimicrobial Effect of Nanomaterials}

To clarify the antimicrobial effect of nanomaterials, we selected two common pathogens that cause crop diseases, namely, Thanatephorus cucumeris (Frank) Donk, which causes rice diseases, and Fusarium oxysporum f. sp. vasinfectum causing cotton diseases. The activated bacteria were added to the LB liquid medium by adding $200 \mu \mathrm{g} \mathrm{ml}^{-1}$ nanomaterials. The OD600 value was measured after $12 \mathrm{~h}$ of incubation at $28^{\circ} \mathrm{C}$. After centrifugation, the bacterial fluid was fixed with $2.5 \%$ glutaraldehyde, dehydrated with gradient ethanol, and vacuum-dried (DZF-6020, Yihen, China). Finally, the morphology of bacteria was observed by using a SEM (JSM6510, JEOL, Japan).

\section{RT-qPCR Analysis}

Plants were grown on half-strength MS media with either BV $\left(200 \mu \mathrm{g} \mathrm{ml}^{-1}\right)$ or without nanomaterials. Approximately, 6-dayold primary roots and 11-day-old roots were harvested. $A D C-1$ (AT2G16500), DAR-2 (AT2G39830), and IQM3 (AT3G52870) were selected to analyze the expression of the taproot, while ARF19 (AT1G19220), CKX1 (AT2G41510), ERF6 (AT4G17490), and IQM3 (AT3G52870) were selected to analyze the expression of the lateral root. Total RNA was isolated using TRIzol reagent (Invitrogen) and converted to complementary DNA (cDNA) using a Transcriptor First Strand cDNA Synthesis Kit (Roche) following the manufacturer's protocol. qPCR was performed using a 7500 Real-time PCR Detection System (Bio-Rad) in conjunction with the Fast Start universal SYBR Green Master Mix (Roche). ACT2 (AT3G18780) was used as a reference gene to normalize the data, and the relative expression levels were calculated using the $2^{-\Delta \Delta C T}$ method, as described previously (Cao et al., 2013). The primers used for qPCR are listed in Supplementary Table S1.

\section{Statistical Analyses}

Without special instructions, all experiments were repeated at least three times. SPSS 20.0 and SigmaPlot 10.0 were used for statistical analysis and plotting. Statistical differences were analyzed by Duncan's test. The data were considered significant in accordance with the following criteria $(p<0.05)$.

\section{RESULTS}

\section{Fabrication and Characterization of Nanomaterial}

The morphology and structures of the as-prepared BV nanomaterials were detected by SEM (Figure 1). Geometrically shaped-like nanoparticles were observed for BV, and their average diameter was approximately $16 \pm 3 \mathrm{~nm}$ (Figure 1A). In addition, $\mathrm{C}, \mathrm{O}, \mathrm{Bi}$, and $\mathrm{V}$ were clearly displayed in the EDS spectra (Figure 1B), confirming the presence of BV nanomaterials. The phase purities and crystallinities of the BV nanomaterials were further characterized by XRD analysis (Figure 1C). Obviously, the diffraction peaks at $2 \theta=18.9^{\circ}, 19.3^{\circ}, 29.3^{\circ}, 30.9^{\circ}$, and $53.6^{\circ}$ revealed the (110), (011), (121), (040), and (161) planes for $\mathrm{BV}$ nanomaterials in the XRD pattern, respectively, indexed to monoclinic scheelite-type BV (JCPDS no. 14-0688).

\section{Effects of Nanomaterial on Arabidopsis Roots}

To confirm the influence of BV on the primary root length and lateral root numbers, these two traits were evaluated after 6 and 11 days of plant growth on the various BV/MS media. Figure 2 shows that the nanomaterial affects the length of primary roots in Arabidopsis, and different concentrations of nanomaterials demonstrated inconsistent changes. Compared with the control, 20, 50, and $100 \mu \mathrm{g} \mathrm{ml}^{-1} \mathrm{BV}$ significantly reduced the length of taproots by approximately $13.0 \sim 20.0 \%$, while $200 \mu \mathrm{g} \mathrm{ml}^{-1}$ BV remarkably enhanced the length by approximately $49.0 \%$. This may imply that BV has a dual effect on the length of plant roots.

In addition, we also observed that the addition of $\mathrm{BV}$ nanomaterials can also affect the lateral root number (Figure 3). BV treatment at different concentrations increased the number of lateral roots of all the plants, and the difference in the $20-\mu \mathrm{g} \mathrm{ml}^{-1}$ treatment was significant. There was no significant difference among the other treatments compared to the treatment without the addition of the nanomaterial. In general, the effect of low concentration was more beneficial to increase the number of lateral roots.

Based on the fact that BV promoted the development of taproots, the influence of $\mathrm{BV}$ nanomaterials was further explored by measuring different positions of roots (Figure 4). $\mathrm{BV}$ treatment enhanced the length of the extension zone, but there was little effect on that of the meristem zone and taproot cap. Therefore, the results suggested that BV might have an effect on the extension zone and leads to an increase in the length of the taproot. Furthermore, the diameter of the primary root was also analyzed. Unfortunately, there was no significant change in the diameter, suggesting that $\mathrm{BV}$ has a limited effect on root diameter. 

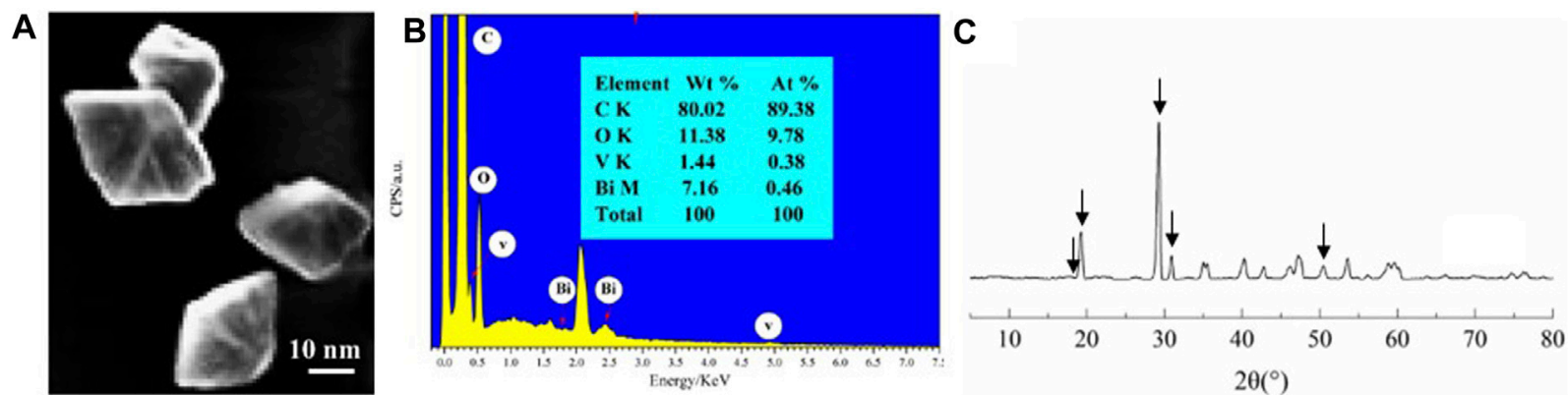

FIGURE 1 | Characterization of BV nanomaterial SEM (A), EDS spectra (B), and XRD patterns (C) images of BV. Arrows indicate the characteristic peak of BV.
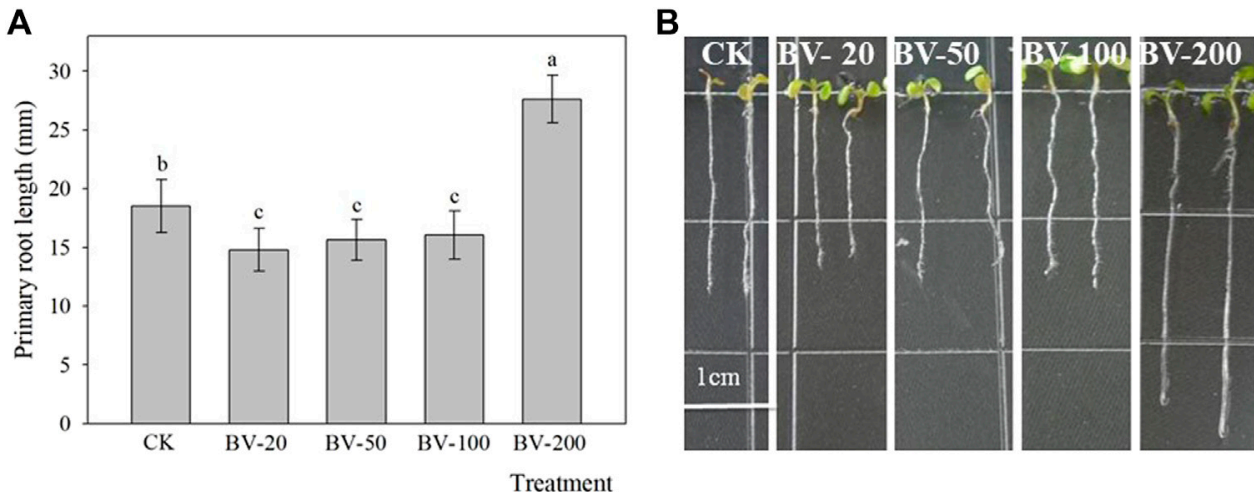

FIGURE 2 | Effects of different concentrations of BV nanomaterial on the primary root length of Arabidopsis. Bar of (A) was standard error. Scale bar = $1 \mathrm{~cm}$. CK, BV-20, BV-50, BV-100, and BV-200 of (A and B) were added to the MS medium with 0, 20, 50, 100, and $200 \mu \mathrm{g} \mathrm{m}{ }^{-1}$ of BV, respectively. $\mathrm{N}=30$. Different lowercase letters above the bar of $(\mathbf{A})$ indicate that there were significant differences among the treatments at $p<0.05$.
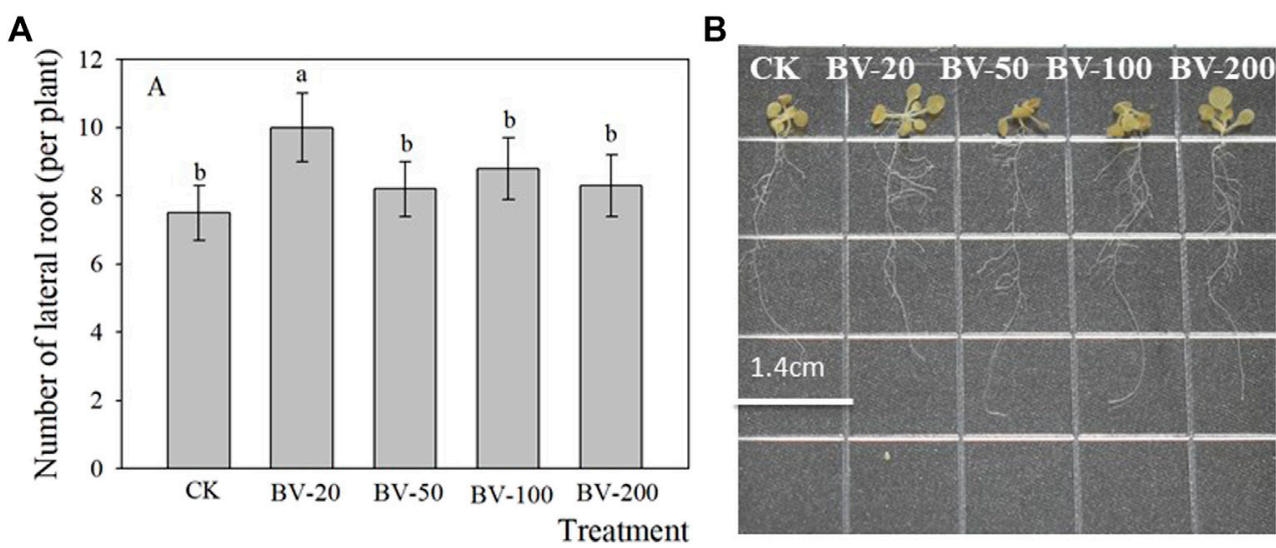

FIGURE 3 | Effects of different concentrations of BV nanomaterials on the number of lateral roots in Arabidopsis. Bar of (A) was standard error. CK, BV-20, BV-50, BV-100, and BV-200 of (A and B) were added to the MS medium with 0, 20, 50, 100, and $200 \mu \mathrm{g} \mathrm{ml}{ }^{-1}$ of BV, respectively. N = 15. Different lowercase letters above the bar of $\mathbf{( A )}$ indicate that there were significant differences among the treatments at $p<0.05$. 

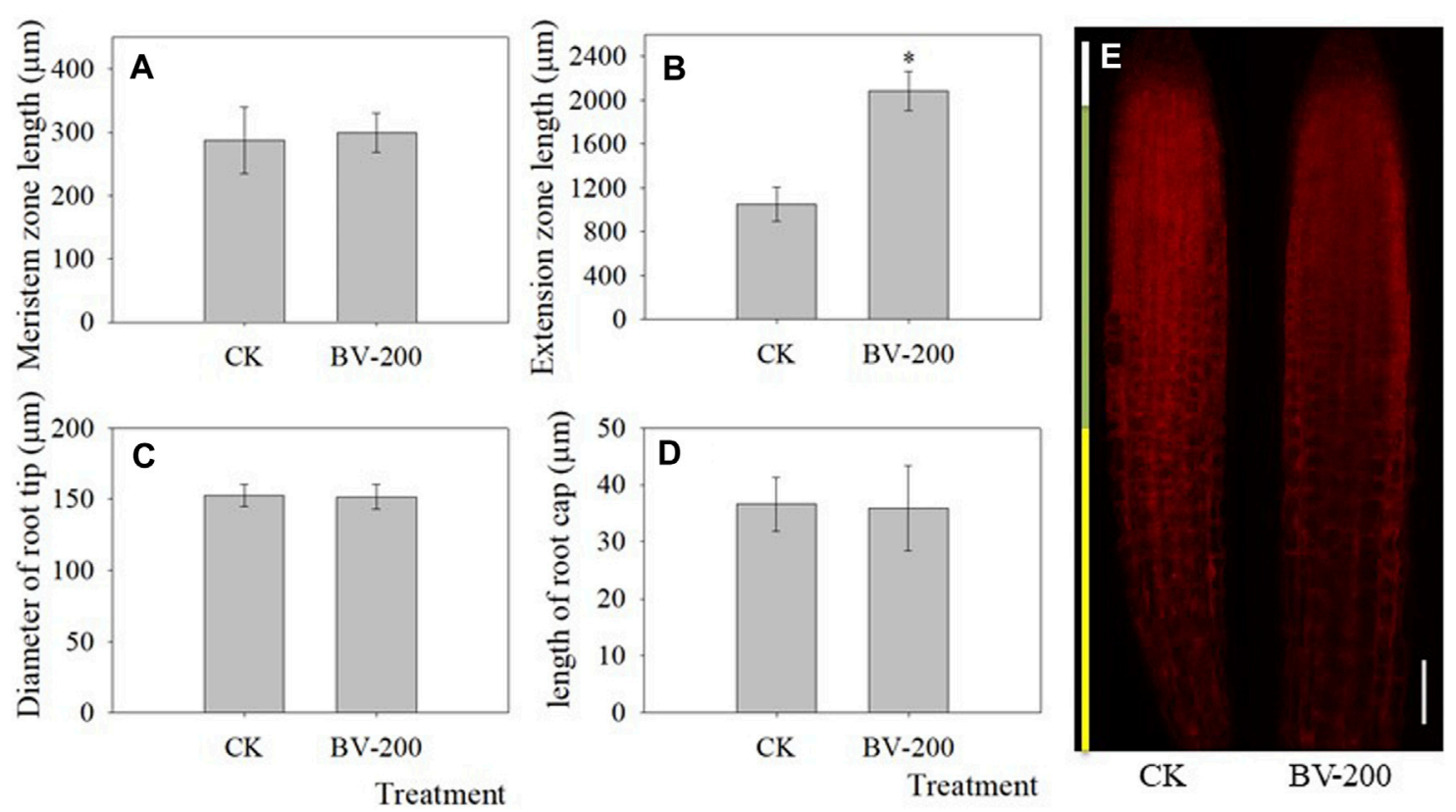

FIGURE 4 | Effect of BV nanomaterials on primary root length in Arabidopsis. (A) Meristem zone length of primary root. (B) Extension zone length of primary root. (C) Diameter of root tip. (D) Length of the taproot cap. (E) Representative images of roots stained with PI to outline the living cells, showing the root cap, meristem domain, and extension zone after 4 days of incubation. Scale bar $=50 \mu \mathrm{m}$. CK: the control without adding BV. BV-200: $200 \mu \mathrm{g} \mathrm{ml}^{-1} \mathrm{BV}$ treatment. $\mathrm{N}=30$. Asterisks above the bar indicate that there were significant differences between the two treatments at $p<0.05$.

\section{The Number and Size of Stomata Increased After BV Treatment}

Since the roots were affected after BV treatment, we decided to observe whether the leaves were also affected. As shown in Figure 5, we found that the number and size of stomata increased significantly. After BV treatment, the number of stomata reached 171, while the number of stomata in the control group was 121 . The stomatal size also showed a similar trend. This indicated that an appropriate amount of BV could promote stomatal development. Interestingly, compared with the control, the area of cells around the stomata was also larger after BV treatment.

\section{BV was Mainly Concentrated in Leaves Rather Than Roots}

Considering that the roots and leaves were affected, we determined the distribution of BV. As shown in the figure, leaf XRD diagrams of BV treatment clearly show the (110) (2 $\theta$ $\left.=18.9^{\circ}\right),(011)\left(2 \theta=19.3^{\circ}\right),(121)\left(2 \theta=29.3^{\circ}\right)$, and $(040)(2 \theta=$ $30.9^{\circ}$ ) characteristics of the crystal peak (Figure 6A). However, the characteristic plane peaks of BV can hardly be seen in the XRD patterns of the roots (Figure 6B). ESD results also showed that there was no accumulation of $\mathrm{BV}$ in roots (Supplementary Figure S1), including the root rip, extension zone, and mature zone (Figures 6C-E), indicating that $\mathrm{BV}$ nanomaterials were mostly distributed in the leaves but had low content in the roots.

\section{The Root Activity and $\mathrm{O}_{2}{ }^{--}$Production Analysis}

The abovementioned experiments showed that BV promoted root and leaf development in plants. Therefore, we tried to clarify whether the root activity and $\mathrm{O}_{2}{ }^{--}$of seedlings also changed. $\mathrm{O}_{2}{ }^{-}$ belongs to the ROS group, which has strong oxidizability. It plays an important role in the physical reaction process (Wang et al., 2007). Consequently, TTC and NBT staining were performed (Figure 7). After growing in the half-strength MS medium for 6 days, we found that the root tip color of $200 \mu \mathrm{g} \mathrm{ml}^{-1} \mathrm{BV}$ was significantly darker than that of the control with TTC staining, indicating that the seedlings treated with appropriate concentrations of nanomaterials increased the root activity of Arabidopsis (Figure 7A). In addition, NBT staining of the leaves showed that the color of the control group was significantly darker than that of BV treatment (Figure 7B). This also indicated that $\mathrm{BV}$ treatment could reduce the production of $\mathrm{ROS}_{2}^{-}$in seedlings.

\section{Antimicrobial Effect of Nanomaterials}

Given the reported antimicrobial activity of BV (Xiang et al., 2019), antimicrobial experiments with BV were performed (Figure 8). We selected two common pathogens that caused crop diseases and found that BV had a significant inhibitory effect on them. Fusarium oxysporum f. sp. vasinfectum can cause Fusarium wilt of cotton, and Thanatephorus cucumeris (Frank) Donk can cause sheath blight of rice. As shown in the figure, the OD600 of these two bacteria decreased significantly in the 

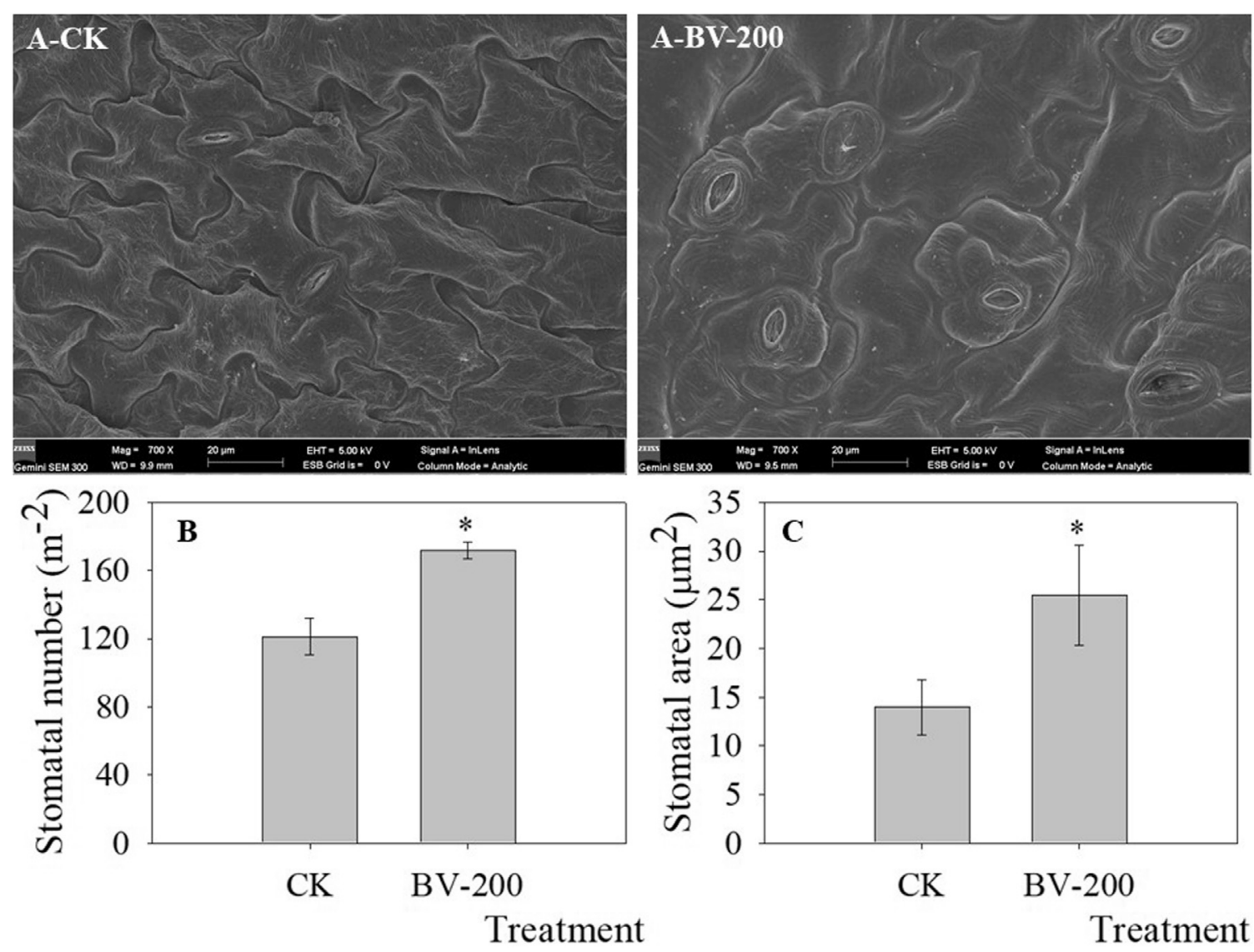

FIGURE 5 | Stomatal density and size in true leaves revealed by SEM. A-CK and A-BV-200 were the control and $200 \mathrm{Mg} \mathrm{ml}^{-1} \mathrm{BV}$, respectively. Bars in Figure A were $20 \mu \mathrm{m}(\mathrm{mag}=700 \times)$. (A) Stomatal number per square (stomatal density). (B) Mean area per stomata (stomatal size, $\mu \mathrm{m}^{2}$ ). Asterisks above the bar indicate that there were significant differences between the two treatments at $p<0.05$.

medium supplemented with BV after $12 \mathrm{~h}$ of culture (Figures 8C,D). In particular, the pathogen of rice sheath blight can be observed directly according to the phenotype. The medium with $\mathrm{BV}$ is very limpid (Figure 8A3), while the medium without BV is very turbid (Figure 8A4). Furthermore, we found that the morphology of both the bacteria changed after adding BV as determined by SEM analysis (Figures 8B2,B4). All of these results showed that $\mathrm{BV}$ had antibacterial activity.

\section{Changes in Gene Expression Related to Root Development in Arabidopsis}

Now that we found that the BV nanomaterial can change root length and lateral root number, some genes related to root development were also further investigated. Therefore, we selected three types of genes, among which two genes mainly affected the primary roots $(A D C 1, D A R 2)$, three genes mainly affected the lateral root (ARF19, CKX1, and ERF6), and one gene affected both (IQM3) (Figure 9). Surprisingly, in the primary roots, $A D C 1, D A R 2$, and IQM3 showed the same trend. After treatment with $\mathrm{BV}$, the expression levels of the three genes were significantly upregulated. These results suggest that BV may be involved in the regulation of plant taproot development in a variety of ways related to hormones and polyamines.

Furthermore, in the lateral root, the related genes show a more complex phenomenon. ARF19, as a gene-mediating hormone regulator of lateral roots, is the most in-depth and clear regulatory pathway (Okushima et al., 2005). In the experiment, BV treatment significantly increased the expression of ARF19. CKX1 could mediate cytokinins to regulate lateral root development, which was significantly downregulated after BV treatment. Moreover, IQM3 showed a similar level between the BV treatment and the control. ERF6 was significantly upregulated in roots treated with $\mathrm{BV}$. All of these results showed that BV can regulate root development by mediating hormones.

\section{DISCUSSION}

$\mathrm{BV}$ is a new type of environmental protection material, and its excellent performance in many fields has been verified (Castiglione et al., 2011). With the widespread use of BV, it will inevitably flow through the environment. $\mathrm{BV}$ is an environmentally friendly and low-carbon metal oxidation 


\section{A}
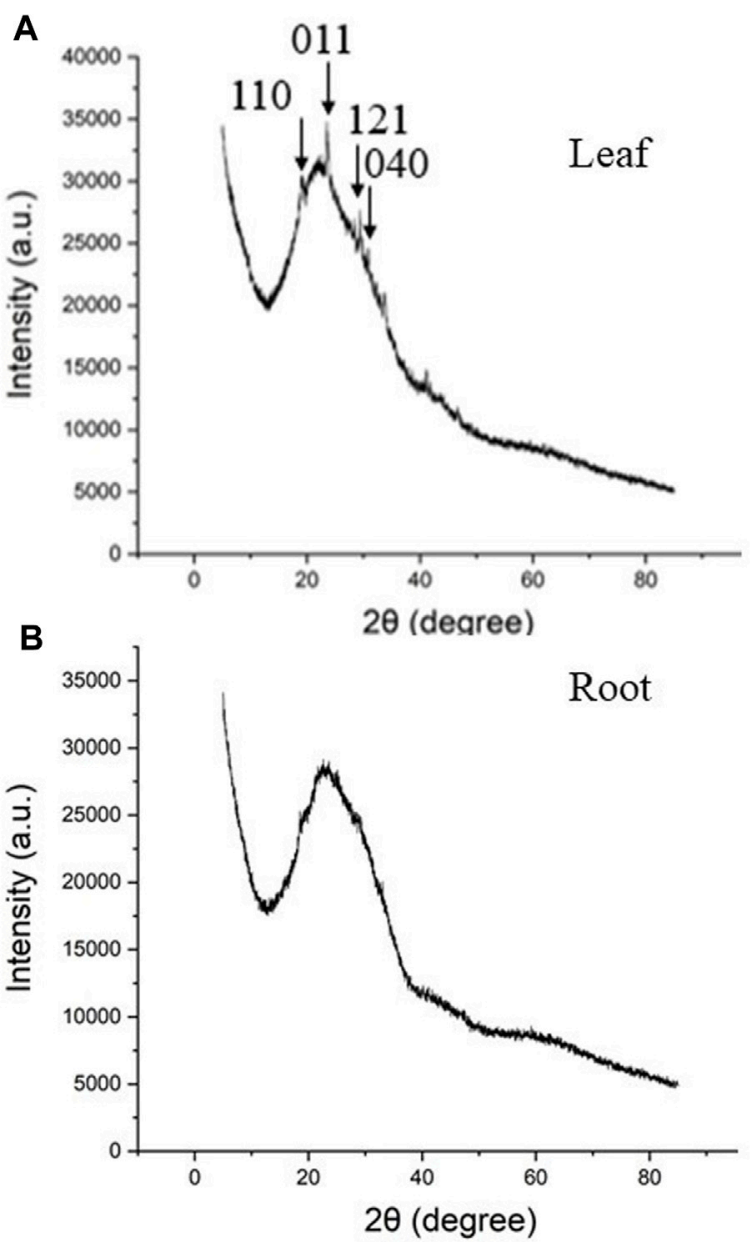

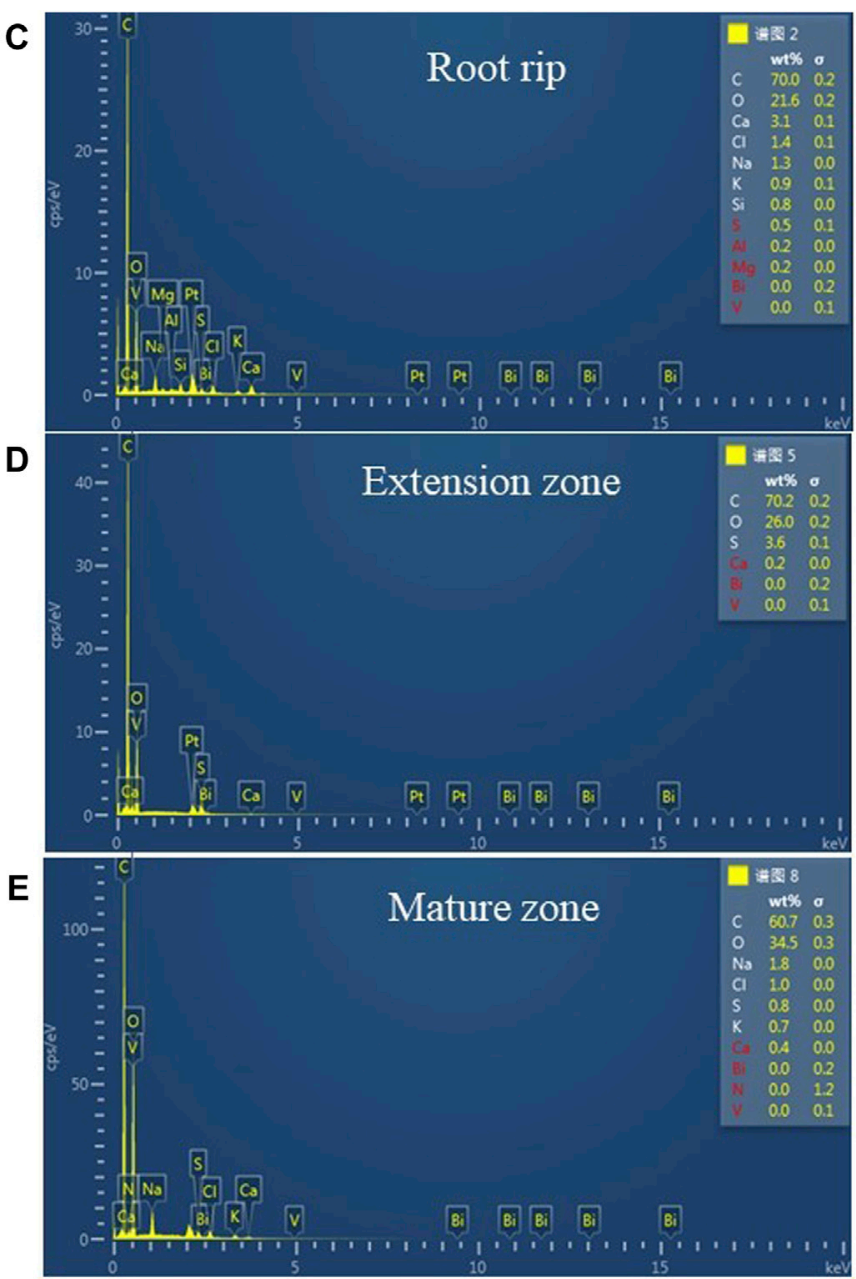

FIGURE 6 | XRD analysis of leaves and taproots and ESD analysis of taproots. (A): XRD analysis of leaves in $200 \mu \mathrm{g} \mathrm{ml^{-1 }} \mathrm{BV}$ treatment. (B): XRD analysis of taproots in $200 \mu \mathrm{g} \mathrm{ml}^{-1} \mathrm{BV}$ treatment. (C): ESD analysis of root tips in taproots in $200 \mu \mathrm{g} \mathrm{ml}^{-1}$ BV treatment. (D): ESD analysis of the extension zone in taproots in $200 \mu \mathrm{g} \mathrm{ml}^{-1}$ BV treatment. (E): ESD analysis of the mature zone in taproots in $200 \mu \mathrm{g} \mathrm{ml}^{-1} \mathrm{BV}$ treatment. The arrow indicates the characteristic peak of BV. $\mathrm{N}=3$.

material (Yin et al., 2010). In this study, considering that BV may be first enriched in plants, we selected the model plant Arabidopsis as the research object to investigate the effects of $\mathrm{BV}$ on plants in terms of many aspects.

We first observed the root changes after BV treatment. Different from most nanomaterials that exert toxicity against plants (Dimkpa et al., 2012; Zou et al., 2016; Yang et al., 2018), root development following treatment with different concentrations of $\mathrm{BV}$ showed an opposite phenomenon (Figures 2,3). We found that root development was promoted by adding an appropriate concentration of $\mathrm{BV}$, while other concentrations inhibited root development. This is similar to some plant growth regulators and indicates a dual nature. This is not the first observation of the phenomenon of dual effects on plants, and a report showed that GO exhibited a similar phenomenon (Park et al., 2020). There may also be another explanation, that is, the dual effects are related to the concentration of BV. This hypothesis is based on the fact that $\mathrm{BV}$ is not detected on the surface and different parts (root rip, exptension zone, and mature zone) of the treated roots observed by EDS (Figures 6C-E and Supplementary Figure S1). This implies that BV plays a role after entering the cells. In contrast to animal cells, plant cells have cell walls and almost no phagocytosis (Tenhaken et al., 2015). Before entering plant cells, nanomaterials must penetrate cell walls and plasma membranes. When the concentration of BV is low, it cannot be well-absorbed by plant roots, so it cannot play a role. When the concentration reaches a certain value, BV can be absorbed by the roots and act. The effect of nanoparticles on cucumber involves a similar mechanism (Zhang et al., 2011). The XRD results also proved this point (Figures 6A,B). However, we need to pay attention to the fact that $\mathrm{BV}$ is not enriched in the root but in the leaf. It is likely that $\mathrm{BV}$ is absorbed by roots and transported to leaves. A similar phenomenon occurs when nanoplastics of different charges accumulate in Arabidopsis (Sun et al., 2020). Although there was no enrichment of $\mathrm{BV}$ in roots, a small amount of $\mathrm{BV}$ was enough to have a significant effect. Further studies found that BV mainly promoted the development of elongated regions, but had 
A
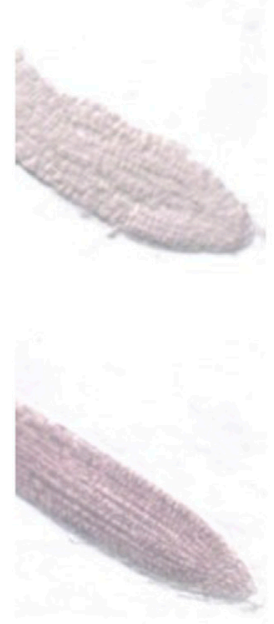

B

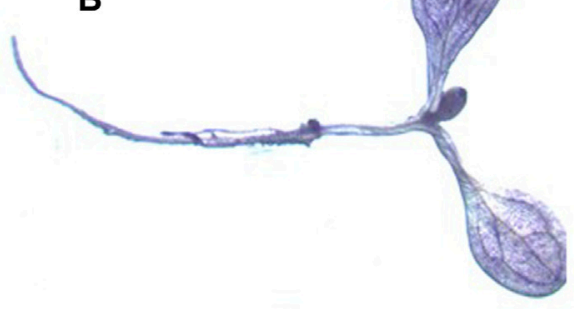

CK

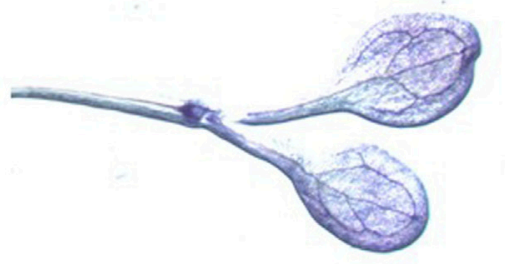

BV-200

FIGURE 7 | Effect of BV nanomaterial treatment on Arabidopsis tissue staining. (A) TTC staining, scale bar = $5 \mathrm{~mm}$. (B) NBT staining, scale bar = $2 \mathrm{~mm}$. CK, the control without BV nanomaterials. BV-200, $200 \mu \mathrm{g} \mathrm{ml}{ }^{-1}$ BV treatment. $\mathrm{N}=6$.
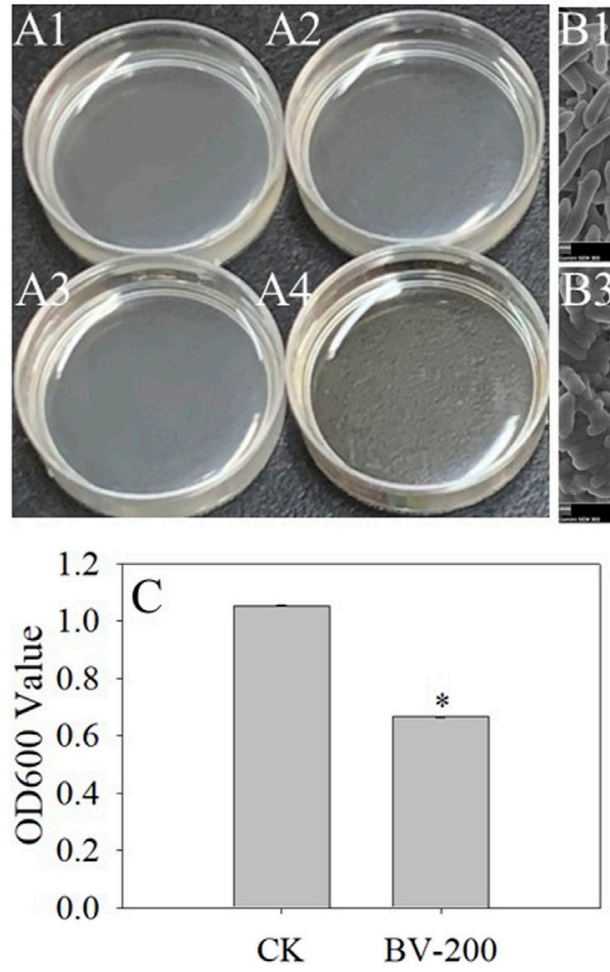

Treatment
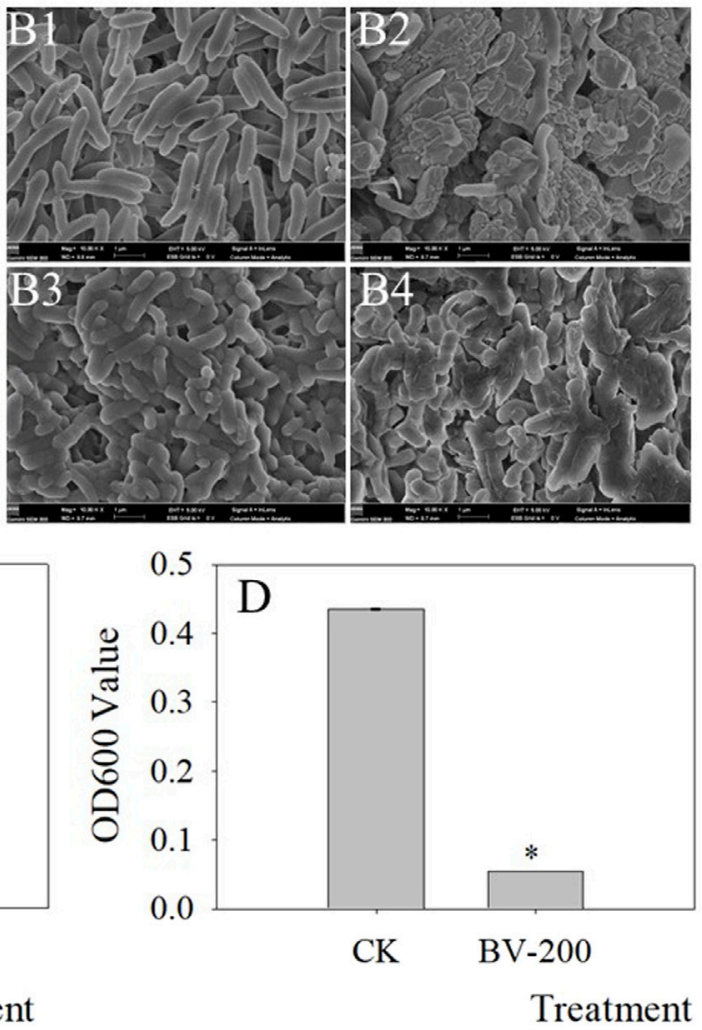

FIGURE 8|Antimicrobial effect of BV nanomaterials. Images of bacterial fluid (A), SEM (B) of bacteria, and OD600 value of bacterial fluid (C,D). A1, A3, B1, and B3 were the controls only with added bacteria. A2, A4, B2, and B4 were the treatments with added bacteria and $200 \mu \mathrm{g} \mathrm{ml^{-1 }}$ BV. A1, A2, B1, and B2 were added to Fusarium oxysporum f. sp. vasinfectum. A3, A4, B3, and B4 were added to Thanatephorus cucumeris (Frank) Donk. Bar of C and D was standard error. Asterisks above the bar of $\mathrm{C}$ and $\mathrm{D}$ indicate that there were significant differences between the treatments at $p<0.05$. $\mathrm{N}=3$. 

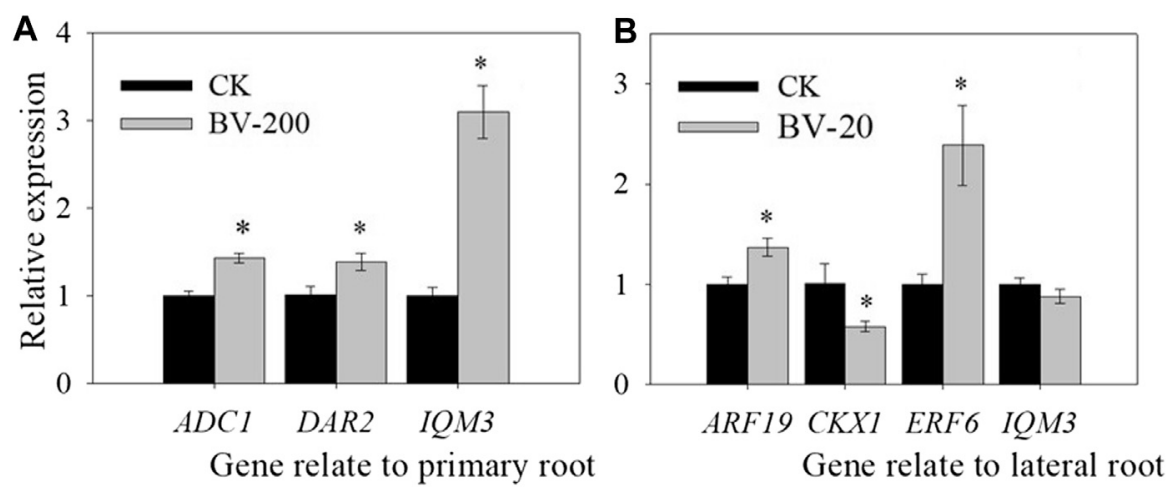

FIGURE 9 | Effect of nanomaterial BV on relative gene expression of primary root length and lateral root numbers in Arabidopsis. (A) Relative gene expression of

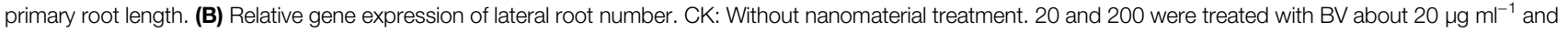
$200 \mathrm{\mu g} \mathrm{ml}^{-1} . \mathrm{N}=3$. Error of figure was standard error. Asterisks above the bar indicate that there were significant differences between the two treatments of the genes at $p<0.05$.

limited effects on other regions. The results of SEM also proved this point (Figure 4). Interestingly, BV not only has dual effects on the development of taproots but also on the development of lateral roots. Previous studies have shown that the development of lateral roots can be affected by many kinds of plant hormones (Zhao et al., 2014). In our study, the effect of BV nanomaterials on lateral roots may be achieved by changing plant hormones. The lateral root is connected to the taproot, and water and nutrients can flow through the catheter and sieve tube (Casimiro et al., 2001). Generally, the growth of lateral roots was inhibited by the growth of taproots, especially near the root tip (Casimiro et al., 2001). To a certain extent, BV treatment was in line with this trend. It is necessary to further study these phenomena, and the cause of these different modes of influence can increase our understanding of how BV affects plants.

Considering that BV can affect the growth of roots, we also observed the leaves (Figure 5). Not surprisingly, we found that the leaves also changed significantly after BV treatment. The most obvious change was that the number and size of stomata expanded. The stomata is an important gas exchange channel between the leaves and air. The regulation of stomatal opening and closing plays an important role in transpiration, photosynthesis, and other important biological processes (Davies et al., 1991). Under drought conditions, plants reduce stomatal opening and closing or even close stomata to reduce transpiration intensity, to reduce water loss to adapt to drought environments (Davies et al., 1991). In addition, stomatal closure can also affect the absorption of $\mathrm{CO}_{2}$ by plants and directly affects the intensity of photosynthesis (Bonan et al., 2008). This means that BV treatment can promote the development of Arabidopsis by affecting stomatal-mediated photosynthesis and transpiration.

In view of the fact that $\mathrm{BV}$ can promote the development of Arabidopsis, we further studied the related physiologic indicators. Subsequently, TTC and NBT staining was performed to observe the root activity and production of ROS in seedlings. When organisms are stressed, the production of ROS in the body will increase greatly and when it exceeds the antioxidant defence capacity of organisms, cellular components such as lipids, proteins and nucleic acids will be irreversibly damaged under the action of $\mathrm{O}_{2}{ }^{--}$to interfere with cell metabolism or cause cell death (Williams et al., 2014). Succinic acid is a key intermediate in the tricarboxylic acid cycle. Under physiologic conditions, succinate dehydrogenase in mitochondria oxidizes succinate to fumaric acid and releases electrons to participate in oxidative phosphorylation (Chouchani et al., 2014). The reduction in TTC indicates that the activity of the dehydrogenase can be used as an indicator of root activity. As a method to identify root vitality, TTC staining is based on the principle that living tissues can produce hydrogen ions under the action of the dehydrogenase and has a reduction ability. The depth of tissue coloration indicates the strength of root activity. After growing in the half-strength MS medium for 6 days, we found that the root tip color of $200 \mu \mathrm{g} \mathrm{ml}^{-1} \mathrm{BV}$ was significantly darker than that of the control, indicating that the seedlings treated with appropriate concentrations of nanomaterials increased the root activity of Arabidopsis seedlings. Xie et al. (2019) also reported that plant root activity and plant root growth were positively related under GO treatment in napus seedlings. This suggests that BV can affect the tricarboxylic acid cycle and plays a positive role in enhancing plant activity. Superoxide dismutase (SOD) is an enzyme that scavenges $\mathrm{O}_{2}{ }^{-}$- (Smith et al., 2003). $\mathrm{O}_{2}{ }^{-}{ }^{-}$can reduce NBT to blue methylhydrazone, so SOD inhibits the formation of methylhydrazone. The deeper the blue color of the tissue treated with the NBT solution, the lower the enzyme activity. In a reverse situation, the enzyme activity is higher. Therefore, this method can be used to measure $\mathrm{O}_{2}{ }^{--}$. In this experiment, we found that Arabidopsis seedlings at $200 \mu \mathrm{g} \mathrm{ml}^{-1} \mathrm{BV}$ were slightly lighter than those of the control, indicating that the accumulation of $\mathrm{O}_{2}{ }^{--}$in seedlings was reduced by an appropriate concentration of BV. Plants respond to nanoparticle-mediated stresses through ROS generation (Begum et al., 2012). It is widely accepted that the toxicity of nanoparticles on plants is commonly evident at high concentrations and attributed to the generation of reactive oxygen species (ROS) (Marslin et al., 2017). However, a report showed that SOD activity was widely stimulated after the exposure of plants to $\mathrm{TiO}_{2} \mathrm{NPs}$ and reduced the level of total 
ROS. Our data are consistent with the results (Melo et al., 2021). This result suggested that BV enhanced the SOD activity and promoted plant growth by reducing the accumulation of ROS. In addition, we also studied the antibacterial activity of BV. The results showed that BV had an obvious inhibitory effect on some pathogens causing crop diseases. This also provides a new potential means for crop disease control. Interestingly, this result can also be used to explain why low concentrations inhibit root development and high concentrations promote root development. Based on the bacteriostatic effect of BV, when it cannot be absorbed by roots, it may inhibit the development of roots when it is free outside the roots.

Finally, we quantitatively studied some genes related to root development to analyze the molecular mechanism by which BV affects root development. ADC1 can affect the synthesis of polyamines in Arabidopsis (Maruri-López et al., 2017), and studies have shown that polyamines can regulate root length (Gurung et al., 2012). DAR2 can be associated with a variety of hormones and then affect the development of the root meristem (Peng et al., 2013). ERF6, as a transcription factor, is also regulated by hormones, thus affecting the development of roots (Eysholdt-Derzsó et al., 2017). In Arabidopsis, the IQM family belongs to the calmodulin-binding protein family with an IQ motif. IQM3 is involved in the regulation of plant root development (Xu et al., 2019). In our study, BV treatment resulted in significant changes in these genes, which can regulate the development of taproots. In the lateral roots, the related genes showed more complex phenomena. In general, BV can affect the expression of plant hormone-related genes and may regulate root development through hormone-mediated pathways.

\section{CONCLUSION}

In our study, BV promoted root development in Arabidopsis by increasing the length of taproots and the number of lateral roots. At the same time, BV also increases the number and size of stomata. The results of tissue staining showed that BV played a positive role and enhanced plant vitality. Moreover, BV had an inhibitory effect on some pathogens causing crop diseases. In addition, the expression levels of root development-related genes changed. In conclusion, proper concentrations of $\mathrm{BV}$ are expected to be used as promoters for plant growth and development. BV is expected to be widely used in plant-related

\section{REFERENCES}

Begum, P., and Fugetsu, B. (2012). Phytotoxicity of Multi-Walled Carbon Nanotubes on Red Spinach (Amaranthus Tricolor L) and the Role of Ascorbic Acid as an Antioxidant. J. Hazard. Mater. 243, 212-222. doi:10.1016/j.jhazmat.2012.10.025

Bonan, G. B. (2008). Forests and Climate Change: Forcings, Feedbacks, and the Climate Benefits of Forests. Science 320, 1444-1449. doi:10.1126/ science. 1155121

Brandhoff, B., Simon, A., Dornieden, A., and Schumacher, J. (2017). Regulation of Conidiation in Botrytis Cinerea Involves the Light-Responsive Transcriptional fields due to its excellent properties, low production cost, and antimicrobial properties. However, there are many problems to be solved. For example, only Arabidopsis was used as an experimental material in this research, whereas how BV affects other plants remains to be explored. Finally, it is necessary to explore the mechanisms by which nanomaterials affect plants and deepen the understanding of these mechanisms.

\section{DATA AVAILABILITY STATEMENT}

The original contributions presented in the study are included in the article/Supplementary Material; further inquiries can be directed to the corresponding author.

\section{AUTHOR CONTRIBUTIONS}

All authors have contributed to the study conception and design. Material preparation, data collection, and analysis were performed by CG, SL, YZW, HX, XXG, YWG, and HYX. The first draft of the manuscript was written by $C G$, and all authors commented on the previous versions of the manuscript. YYC, HHY, and BHW critically revised the manuscript. All authors have read and approved the manuscript.

\section{FUNDING}

The National Natural Science Foundation of China (81801856) and the Natural Science Foundation of Jiangsu Province (BK20180949) of HHY. The National Natural Science Foundation of China (32000965) and the Natural Science Foundation of Jiangsu Province (BK20200964) of HYX. The National Natural Science Foundation of China (32172104) and the open fund of the Nantong University large scale instrument (KFJN2131) of YYC.

\section{SUPPLEMENTARY MATERIAL}

The Supplementary Material for this article can be found online at: https://www.frontiersin.org/articles/10.3389/fchem.2021.766078/ full\#supplementary-material

Regulators BcLTF3 and BcREG1. Curr. Genet. 63, 931-949. doi:10.1007/ s00294-017-0692-9

Cao, Y., Zhang, Q., Chen, Y., Zhao, H., Lang, Y., Yu, C., et al. (2013). Identification of Differential Expression Genes in Leaves of Rice (Oryza sativaL.) in Response to Heat Stress by cDNA-AFLP Analysis. Biomed. Res. Int. 2013, 1-11. doi:10.1155/2013/576189

Casimiro, I., Marchant, A., Bhalerao, R. P., Beeckman, T., Dhooge, S., Swarup, R., et al. (2001). Auxin Transport Promotes Arabidopsis Lateral Root Initiation. Plant Cell 13, 843-852. doi:10.1105/tpc.13.4.843

Chouchani, E. T., Pell, V. R., Gaude, E., Aksentijević, D., Sundier, S. Y., Robb, E. L., et al. (2014). Ischaemic Accumulation of Succinate Controls Reperfusion Injury through Mitochondrial ROS. Nature 515, 431-435. doi:10.1038/nature13909 
Davies, W. J., and Zhang, J. (1991). Root Signals and the Regulation of Growth and Development of Plants in Drying Soil. Annu. Rev. Plant Physiol. Plant Mol. Biol. 42, 55-76. doi:10.1146/annurev.pp.42.060191.000415

de Melo, G. S. R., Constantin, R. P., Abrahão, J., de Paiva Foletto-Felipe, M., Constantin, R. P., dos Santos, W. D., et al. (2021). Titanium Dioxide Nanoparticles Induce Root Growth Inhibition in Soybean Due to Physical Damages. Water Air Soil Pollut. 232, 25. doi:10.1007/s11270-020-04955-7

Dimkpa, C. O., Mclean, J. E., Latta, D. E., Manangón, E., Britt, D. W., Johnson, W. P., et al. (2012). $\mathrm{CuO}$ and $\mathrm{ZnO}$ Nanoparticles: Phytotoxicity, Metal Speciation, and Induction of Oxidative Stress in Sand-Grown Wheat. J. Nanopart Res. 14, 1125. doi:10.1007/s11051-012-1125-9

Eysholdt-Derzsó, E., and Sauter, M. (2017). Root Bending Is Antagonistically Affected by Hypoxia and ERF-Mediated Transcription via Auxin Signaling. Plant Physiol. 175, 412-423. doi:10.1104/pp.17.00555

Ghodake, G., Seo, Y. D., Park, D., and Lee, D. S. (2010). Phytotoxicity of Carbon Nanotubes Assessed by Brassica Juncea and Phaseolus Mungo. J. Nanoelectron. Optoelectron. 5, 157-160. doi:10.1166/jno.2010.1084

Gómez-Merino, F. C., Trejo-Téllez, L. I., García-Jiménez, A., Escobar-Sepúlveda, H. F., and Ramírez-Olvera, S. M. (2020). Silicon Flow from Root to Shoot in Pepper: a Comprehensive In Silico Analysis Reveals a Potential Linkage between Gene Expression and Hormone Signaling that Stimulates Plant Growth and Metabolism. Peer J. 8, e10053. doi:10.7717/peerj.10053

Gopalakrishnan Nair, P. M., Kim, S.-H., and Chung, I. M. (2014). Copper Oxide Nanoparticle Toxicity in Mung Bean (Vigna Radiata L.) Seedlings: Physiological and Molecular Level Responses of In Vitro Grown Plants. Acta Physiol. Plant 36, 2947-2958. doi:10.1007/s11738-014-1667-9

Guan, D. L., Niu, C. G., Wen, X. J., Guo, H., Deng, C. H., and Zeng, G. M. (2018). Enhanced Escherichia coli Inactivation and Oxytetracycline Hydrochloride Degradation by a Z-Scheme Silver Iodide Decorated Bismuth Vanadate Nanocomposite under Visible Light Irradiation. J. Colloid Interf. Sci. 512, 272-281. doi:10.1016/j.jcis.2017.10.068

Gurung, S., Cohen, M. F., Fukuto, J., and Yamasaki, H. (2012). Polyamine-induced Rapid Root Abscission in Azolla Pinnata. J. Amino Acids 2012, 1-9. doi:10.1155/2012/493209

Hao, S., Zhang, L., Wang, X., Zhao, G., Hou, P., and Xu, X. (2021). Design of Multilayered Porous Aluminum Nitride for Supercapacitor Applications. Energy Fuels 35, 12628-12636. doi:10.1021/acs.energyfuels.1c01420

Ibañez, C., Poeschl, Y., Peterson, T., Bellstädt, J., Denk, K., Gogol-Döring, A., et al. (2017). Ambient Temperature and Genotype Differentially Affect Developmental and Phenotypic Plasticity in Arabidopsis thaliana. BMC Plant Biol. 17, 114. doi:10.1186/s12870-017-1068-5

Kim, J. Y., Song, J. T., and Seo, H. S. (2017). COP1 Regulates Plant Growth and Development in Response to Light at the post-translational Level. J. Exp. Bot. 68, 4737-4748. doi:10.1093/jxb/erx312

Kong, X., Tian, H., Yu, Q., Zhang, F., Wang, R., Gao, S., et al. (2018). PHB3 Maintains Root Stem Cell Niche Identity through ROS-Responsive AP2/ERF Transcription Factors in Arabidopsis. Cel Rep. 22, 1350-1363. doi:10.1016/ j.celrep.2017.12.105

Lahiani, M. H., Dervishi, E., Chen, J., Nima, Z., Gaume, A., Biris, A. S., et al. (2013). Impact of Carbon Nanotube Exposure to Seeds of Valuable Crops. ACS Appl. Mater. Inter. 5, 7965-7973. doi:10.1021/am402052x

Marslin, G., Sheeba, C. J., and Franklin, G. (2017). Nanoparticles Alter Secondary Metabolism in Plants via Ros Burst. Front. Plant Sci. 8, 1-8. doi:10.3389/ fpls.2017.00832

Maruri-López, I., and Jiménez-Bremont, J. F. (2017). Hetero- and Homodimerization of Arabidopsis thaliana Arginine Decarboxylase AtADC1 and AtADC2. Biochem. Biophysical Res. Commun. 484, 508-513. doi:10.1016/ j.bbrc.2017.01.083

Mondal, A., Basu, R., Das, S., and Nandy, P. (2011). Beneficial Role of Carbon Nanotubes on Mustard Plant Growth: an Agricultural prospect. J. Nanopart Res. 13, 4519-4528. doi:10.1007/s11051-011-0406-z

Nagaonkar, D., Shende, S., and Rai, M. (2015). Biosynthesis of Copper Nanoparticles and its Effect on Actively Dividing Cells of Mitosis inAllium Cepa. Biotechnol. Prog. 31, 557-565. doi:10.1002/btpr.2040

Napsucialy-Mendivil, S., Alvarez-Venegas, R., Shishkova, S., and Dubrovsky, J. G. (2014). Arabidopsis Homolog of Trithorax1 (ATX1) Is Required for Cell Production, Patterning, and Morphogenesis in Root Development. J. Exp. Bot. 65, 6373-6384. doi:10.1093/jxb/eru355
Nazaralian, S., Majd, A., Irian, S., Najafi, F., Ghahremaninejad, F., Landberg, T., et al. (2017). Comparison of Silicon Nanoparticles and Silicate Treatments in Fenugreek. Plant Physiol. Biochem. 115, 25-33. doi:10.1016/ j.plaphy.2017.03.009

Ogunkunle, C. O., Odulaja, D. A., Akande, F. O., Varun, M., Vishwakarma, V., and Fatoba, P. O. (2020). Cadmium Toxicity in Cowpea Plant: Effect of Foliar Intervention of Nano- $\mathrm{TiO}_{2}$ on Tissue Cd Bioaccumulation, Stress Enzymes and Potential Dietary Health Risk. J. Biotechnol. 310, 54-61. doi:10.1016/ j.jbiotec.2020.01.009

Okushima, Y., Overvoorde, P. J., Arima, K., Alonso, J. M., Chan, A., Chang, C., et al. (2005). Functional Genomic Analysis of the Auxin Response Factor Gene Family Members in Arabidopsis Thaliana: Unique and Overlapping Functions of ARF7 and ARF19. Plant Cell 17, 444-463. doi:10.1105/tpc.104.028316

Park, S., Choi, K. S., Kim, S., Gwon, Y., and Kim, J. (2020). Graphene OxideAssisted Promotion of Plant Growth and Stability. Nanomaterials 10, 758. doi:10.3390/nano10040758

Peng, Y., Chen, L., Lu, Y., Ma, W., Tong, Y., and Li, Y. (2013). DAR2 Acts as an Important Node Connecting Cytokinin, Auxin, SHY2 and PLT1/2 in Root Meristem Size Control. Plant Signal. Behav. 8, e24226. doi:10.4161/ psb. 24226

Regmi, C., Dhakal, D., and Lee, S. W. (2018). Visible-light-induced $\mathrm{Ag} / \mathrm{BiVO}_{4}$ Semiconductor with Enhanced Photocatalytic and Antibacterial Performance. Nanotechnology 29, 064001. doi:10.1088/1361-6528/aaa052

Ruffini Castiglione, M., Giorgetti, L., Geri, C., and Cremonini, R. (2011). The Effects of Nano- $\mathrm{TiO}_{2}$ on Seed Germination, Development and Mitosis of Root Tip Cells of Vicia Narbonensis L. And Zea mays L. J. Nanopart Res. 13, 2443-2449. doi:10.1007/s11051-010-0135-8

Sarkar, S., and Chattopadhyay, K. K. (2012). Size-dependent Optical and Dielectric Properties of $\mathrm{BiVO}_{4}$ Nanocrystals. Physica E: Low-Dimens. Syst. Nanostructures 44, 1742-1746. doi:10.1016/j.physe.2011.11.019

Sharma, R., Uma, S., Singh, S., Verma, A., and Khanuja, M. (2016). Visible Light Induced Bactericidal and Photocatalytic Activity of Hydrothermally Synthesized BiVO 4 Nano-Octahedrals. J. Photochem. Photobiol. B: Biol. 162, 266-272. doi:10.1016/j.jphotobiol.2016.06.035

Sivakumar, V., Suresh, R., Giribabu, K., and Narayanan, V. (2015). BiVO4 Nanoparticles: Preparation, Characterization and Photocatalytic Activity. Cogent Chem. 1, 1074647. doi:10.1080/23312009.2015.1074647

Smith, R. A. J., Kelso, G. F., Blaikie, F. H., Porteous, C. M., Ledgerwood, E. C., Hughes, G., et al. (2003). Using Mitochondria-Targeted Molecules to Study Mitochondrial Radical Production and its Consequences. Biochem. Soc. Trans. 31, 1295-1299. doi:10.1042/bst0311295

Sun, W., Ma, Z., Chen, H., and Liu, M. (2019). MYB Gene Family in Potato (Solanum tuberosum L.): Genome-wide Identification of Hormone-Responsive Reveals Their Potential Functions in Growth and Development. Int. J. Mol. Sci. 20, 4847. doi:10.3390/ijms20194847

Sun, X. D., Yuan, X. Z., Jia, Y., Feng, L. J., Zhu, F. P., Dong, S. S., et al. (2020). Differentially Charged Nanoplastics Demonstrate Distinct Accumulation in Arabidopsis thaliana. Nat. Nanotechnol. 15, 755-760. doi:10.1038/s41565-0200707-4

Tanaka, J., Kiyoshi, K., Kadokura, T., Suzuki, K.-i., and Nakayama, S. (2021). Elucidation of the Enzyme Involved in 2,3,5-triphenyl Tetrazolium Chloride (TTC) Staining Activity and the Relationship between TTC Staining Activity and Fermentation Profiles in Saccharomyces cerevisiae. J. Biosci. Bioeng. 131, 396-404. doi:10.1016/j.jbiosc.2020.12.001

Tenhaken, R. (2015). Cell wall Remodeling under Abiotic Stress. Front. Plant Sci. 5, 771. doi:10.3389/fpls.2014.00771

Thuesombat, P., Hannongbua, S., Akasit, S., and Chadchawan, S. (2014). Effect of Silver Nanoparticles on rice (Oryza Sativa L. Cv. KDML 105) Seed Germination and Seedling Growth. Ecotoxicology Environ. Saf. 104, 302-309. doi:10.1016/ j.ecoenv.2014.03.022

Wang, L., Gong, L., Zhao, E., Yu, Z., Torimoto, Y., Sadakata, M., et al. (2007). Inactivation of Escherichia coli by O?water. Lett. Appl. Microbiol. 45, 200-205. doi:10.1111/j.1472-765X.2007.02170.x

Williams, J. S., and Kunkel, T. A. (2014). Ribonucleotides in DNA: Origins, Repair and consequencesOrigins Repairand Consequences. DNA Repair 19, 27-37. doi:10.1016/j.dnarep.2014.03.029

Xiang, Z., Wang, Y., Yang, Z., and Zhang, D. (2019). Heterojunctions of $\beta$-AgVO3/ BiVO4 Composites for Enhanced Visible-Light-Driven Photocatalytic 
Antibacterial Activity. J. Alloys Compd. 776, 266-275. doi:10.1016/ j.jallcom.2018.10.287

Xie, L. L., Chen, F., Zou, X. L., Shen, S. S., Wang, X. G., Yao, G. X., et al. (2019). Graphene Oxide and ABA Cotreatment Regulates Root Growth of Brassica Napus L. By Regulating IAA/ABA. J. Plant Physiol. 240, 153007. doi:10.1016/ j.jplph.2019.153007

Xu, H., Feng, Y., Fan, T., Lü, T., Xie, C., Zhou, Y., et al. (2019). Disruption of IQM3 Reduce the Number of Lateral Roots and Increases the Length of Primary Root in Arabidopsis Seedlings. Plant Physiol. J. 55, 629-634. doi:10.13592/ j.cnki.ppj.2019.1001

Yang, J., Jiang, F., Ma, C., Rui, Y., Rui, M., Adeel, M., et al. (2018). Alteration of Crop Yield and Quality of Wheat upon Exposure to Silver Nanoparticles in a Life Cycle Study. J. Agric. Food Chem. 66, 2589-2597. doi:10.1021/ acs.jafc.7b04904

Yin, W., Wang, W., Zhou, L., Sun, S., and Zhang, L. (2010). CTAB-assisted Synthesis of Monoclinic $\mathrm{BiVO}_{4}$ Photocatalyst and its Highly Efficient Degradation of Organic Dye under Visible-Light Irradiation. J. Hazard. Mater. 173, 194-199. doi:10.1016/j.jhazmat.2009.08.068

Zhang, Z., He, X., Zhang, H., Ma, Y., Zhang, P., Ding, Y., et al. (2011). Uptake and Distribution of Ceria Nanoparticles in Cucumber Plants. Metallomics 3, 816-822. doi:10.1039/c1mt00049g

Zhao, G., Cheng, Y., Wu, Y., Xu, X., and Hao, X. (2018). New 2D Carbon Nitride Organic Materials Synthesis with Huge-Application Prospects in CN Photocatalyst. Small 14, 1704138. doi:10.1002/ smll.201704138

Zhao, G., Hao, S., Guo, J., Xing, Y., Zhang, L., and Xu, X. (2021). Design of P-N Homojunctions in Metal-free Carbon Nitride Photocatalyst for
Overall Water Splitting. Chin. J. Catal. 42, 501-509. doi:10.1016/ S1872-2067(20)63670-1

Zhao, Y., Xing, L., Wang, X., Hou, Y. J., Gao, J., Wang, P., et al. (2014). The ABA Receptor PYL8 Promotes Lateral Root Growth by Enhancing MYB77dependent Transcription of Auxin-Responsive Genes. Sci. Signal. 7, ra53. doi:10.1126/scisignal.2005051

Zou, X., Li, P., Huang, Q., and Zhang, H. (2016). The Different Response Mechanisms of Wolffia Globosa: Light-Induced Silver Nanoparticle Toxicity. Aquat. Toxicol. 176, 97-105. doi:10.1016/j.aquatox.2016.04.019

Conflict of Interest: The authors declare that the research was conducted in the absence of any commercial or financial relationships that could be construed as a potential conflict of interest.

Publisher's Note: All claims expressed in this article are solely those of the authors and do not necessarily represent those of their affiliated organizations, or those of the publisher, the editors, and the reviewers. Any product that may be evaluated in this article, or claim that may be made by its manufacturer, is not guaranteed or endorsed by the publisher.

Copyright (C) $2021 \mathrm{Gao}, \mathrm{Lu}$, Wang, Xu, Gao, Gu, Xuan, Wang, Yuan and Cao. This is an open-access article distributed under the terms of the Creative Commons Attribution License (CC BY). The use, distribution or reproduction in other forums is permitted, provided the original author(s) and the copyright owner(s) are credited and that the original publication in this journal is cited, in accordance with accepted academic practice. No use, distribution or reproduction is permitted which does not comply with these terms. 